\title{
Problem Base and Case Study Methodology in Medical Education
}

\author{
Shalva Zarnadze MD.MPH.PhD \\ Irine Zarnadze MD.MPH.PhD \\ Levan Baramidze MD.MPH.PhD \\ Zurab Sikharulidze MD.PhD \\ Devi Tabidze MD.PhD \\ Tamar Bakradze MA (in American Studies) \\ Tbilisi State Medical University, Tbilisi, Georgia
}

Doi: 10.19044/esj.2018.c5p9 $\quad$ URL:http://dx.doi.org/10.19044/esj.2018.c5p9

\begin{abstract}
Objectives: EBM (Evidence-Based Medicine) and Case Study is a relatively new concept in medicine, and medical education, but one that is rapidly gaining acceptance as an important approach in assisting medical students, residents, and practicing physicians in their clinical decisionmaking.

Problem Base and Case Study learning in Medical Education has become a widespread and effective method of using the medical literature. It has four basic steps: the development of a clinical question, the literature search for the appropriate medical literature to address the clinical question, critical appraisal of the acquired paper, and application of the results of the research paper to the patient at hand.

Goals: Analysis of effectiveness of teaching methodology

Methods: Observational Study

Results: The use of $\mathrm{PB}(\mathrm{EBM})$ and $\mathrm{CS}$ should allow patient care that is the most effective, the most cost-effective, and the safest.

The skills to master in use the EBM approach include that of question formulation, literature searching, critical appraisal of articles, and application of evidence. The resources needed include computers and Internet for access to full articles, a printer, and functional use of the English language. Moreover, this is a lifelong endeavor, so practice and mentorship are useful. The PB and CS component in the Tbilisi State Medical University has the aim of assisting students in learning objectives. Training in the PB and CS learning method will be provided at the beginning of the Module.
\end{abstract}


Problem base and Case Study learning in education has become a widespread and effective method of literature use. It has four basic steps: the development of a clinical question, the Literature search for the appropriate medical literature to address the clinical question, critical appraisal of the acquired paper, and application of the results of the research paper to the patient at hand.

Conclusion: By the end of this course you should have demonstrated your capacity to: recognize, compare, and contrast the general "ways of thinking" of science (biology) and of philosophy (ethics).

Approach bioethical problems, break them into smaller component parts (analysis), and discuss those analyses through oral and written communication, both individually and in groups.

Approach bioethical problems and propose solutions to them that transcend the disciplines of biology and philosophy, solidly rooted in their respective ways-of-knowing.

Acquire and separate factual knowledge from opinion in the areas of science and philosophy. Demonstrate good critical thinking (that is, clear, logical (coherent and relevant), broad, deep, and discriminating) in bioethics through speaking and writing.

Outcomes of PBL and CS are the problem-solving skills, self-directed learning skills, ability to find and use appropriate resources, critical thinking, measurable knowledge base, performance ability, social and ethical skills, self-sufficiency and self-motivation, leadership skills, ability to work on a team, communication skills, proactive thinking, congruence with workplace skills.

Keywords: PB, EBM,Case Study

\section{Introduction}

PB, EBM (Evidence-Based Methodology) and case study is a relatively new concept in education, but one that is rapidly gaining acceptance as an important approach in assisting students, residents, and practicing physicians in their clinical decision-making.

Problem base leaning and case study in education has become a widespread and effective method of literature use. It has four basic steps: the development of a clinical question, the literature search for the appropriate medical literature to address the clinical question, critical appraisal of the acquired paper, and application of the results of the research paper to the patient at hand. 


\section{Materials and Methods}

Observational Study.

\section{Results and Discussion}

The use of PB (EBM) and CS should allow the patient care that is the most effective possible, the most cost-effective, and the safest.

The skills to be mastered in use the EBM approach include that of question formulation, literature search, critical appraisal of articles, and application of evidence. The resources needed include computers and Internet for access to full articles, a printer, and functional use of the English language. Moreover, this is a lifelong endeavor, so practice and mentorship are useful. $\mathrm{PB}$ and $\mathrm{CS}$, is a rapidly changing field, Huge amount of literature/research, Slow dissemination of new data.

The PB and CS component in the Tbilisi State Medical University has the aim of assisting students in learning objectives. Training in the PB and CS learning method will be provided at the beginning of the Module.

Characteristics of PBL and CS in teaching curricula in TSMU : Problems form the organising focus and stimulus for learning, problems are a vehicle for the development of problem-solving skills, new information is acquired through self- directed learning, learning is student centred, learning occurs in small student groups, teachers are facilitators or guides.

Problems form the organising focus and stimulate learning. Process of PBL : Students confront a problem, students work in groups to alleviate prior knowledge and attempt to identify the nature of the problem, pose questions about what they do not understand, design a plan to solve the problem and identify the resources they need.

Role of the tutor: facilitator, helps to conduct discussions, suggests avenues of investigation, sets problem in a meaningful context, suggests prioritising learning issues, intervenes in negative group dynamics, guides discussions in a group setting.

Objectives of individual or team research: Understand EBM- What it is, why it is important, apply EBM, teach EBM, access EBM resources, GOALS of EBM, Improve outcomes, improve safety, Improve costeffectiveness.

Criteria or indicators of teaching concepts:

WHY USE EBM- Medicine is a rapidly changing field, huge amount of literature/research slow dissemination of new data.

GOALS of EBM; Improve patient's medical situation, improve patient's safety, improve cost-effectiveness;

DOMAINS of EBM: Diagnosis, Therapy, Prognosis, Harm / Etiology, Clinical Practice Guidelines, Systematic Reviews. 
How do we practice EBM? Clinical Question, Literature Search, Critical Appraisal Application of Results, Self-Evaluation \& Improvement.

KEY to EBM PRACTICE: Answerable, Searchable, Appraisable, Applicable.

SPECIFICS: Cases, Worksheets, Pre \& Post tests, Inpatients, Outpatients, Journal Club, Group Sessions, Grand Rounds, Lectures.

Clinical Queries is a pre-set study design filter that is applied to a concept search entered by the searcher Caveats: Filters were validated for indexing applied 1991+ but PubMed automatically searches 1966+; results not always dependable;

Filters are based on assumptions that do not always apply e.g. randomized controlled trials for Harm q's are not included in a Harm filtered search;

Keep concept search as simple as possible, using MeSH terms, for better success

Write out your question $\rightarrow$ PIO;

Identify the key concepts from the question;

Consider/determine the standard medical terminology for each term and other related terms;

Group similar terms together (if necessary) using OR; search each concept independently;

Gather all concepts together using and evaluate and refine approach as necessary;

Understand the various study designs appropriate for therapy trials;

Understand the fundamental concepts in appraising a therapy trial;

Ability to appraise a therapy trial;

Types of Therapy Studies: Phase I: Safety study: novel intervention;

Phase II: Dose Finding: generally not randomized;

Phase III: Large Clinical Trial (e.g. Randomized Controlled Trial): comparison to either placebo or standard of care;

Meta-Analysis: A summary of individual studies (i.e. RCTs) with homogenous data that is pooled and upon which statistical analysis is performed;

Applying limits is useful as it can narrow down large results into a manageable number fairly easily. The following can be applied as limits: Publication type: randomized controlled trial, practice guidelines, reviews, publication date, age, human or animal studies, language.

Resources: Reviews or Clinical Practice Guidelines: PubMed, Cochrane Library, National Guideline Clearinghouse, various association websites;

Evidence-Based Resources: Cochrane Library, Clinical Queries filter in PubMed, Clinical Evidence Journals: citation databases such as PubMed. Types of literature :Primary - RCT, Secondary-synopsis, Tertiary-textbooks. 
Teaching experience in TSMU include development of class activities, leading lab discussions, and grading classroom assignments (with preceptor review), implementation of holistic models. (Fig.1) .

Adherence to ethical norms, understanding and value the importance of the ethical implications of research, appropriately interpret and explain the research results, explain complex ethical concepts to peers. Identify original, research study questions that can advance scientific knowledge about a topic of significance to the ethics, review and synthesize a body of research literature.

Identify and apply interdisciplinary theoretical knowledge and conceptual models to the investigation, select appropriate research designs and methodologies to address questions of ethical importance, understand and appropriately apply analytical strategies used in ethical research.

Generally, the teaching requirements that are in effect at the time of a student's matriculation remain in effect for that student, regardless of changes that occur during the time of the student's progress through the program.

TSMU experience system include course development-classroom technique, student mentoring/guidance, grading development course objectives, selecting appropriate readings, developing classroom activities, developing evaluations, facilitating class discussion (e.g., staying on topic, eliciting input from all students, guiding discussion toward learning objective).

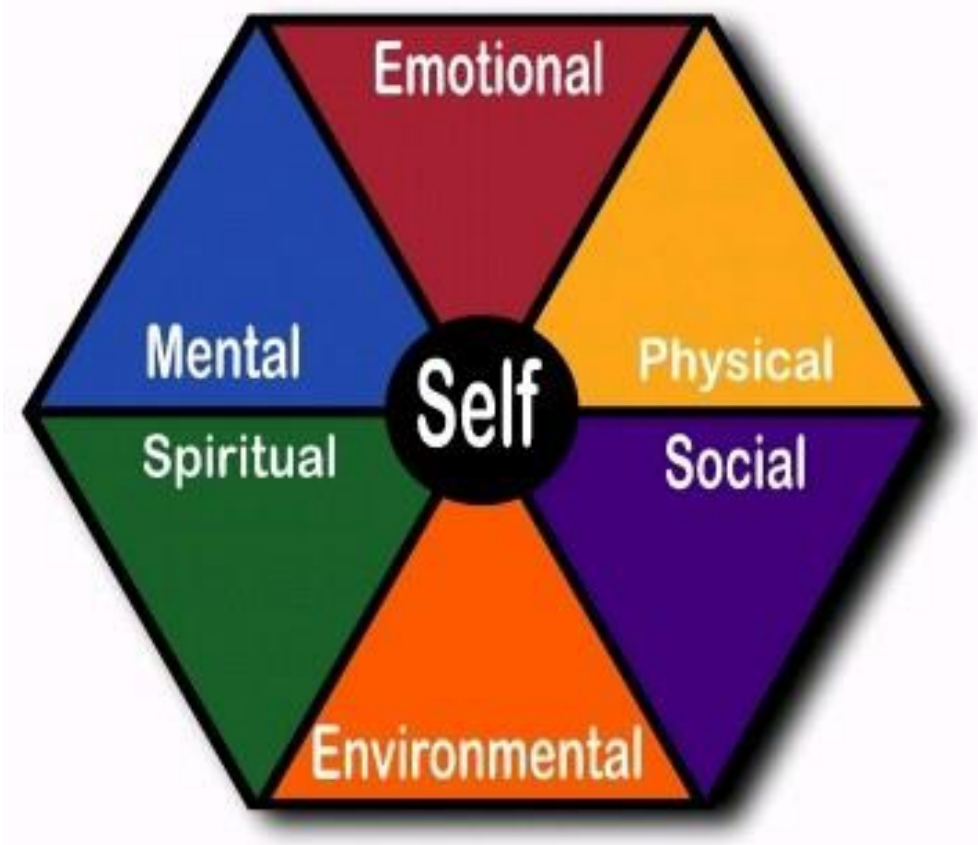

Fig. 1 Holistic Model 
Discussion about implementation: Why should we focus our efforts on holistic \& wellness?

Current Interventions for Holistic \& Wellness, What are we currently using?

Why should we focus our efforts on holistic \& wellness?

- $\quad$ Future Interventions for Holistic \& Wellness

- What is the future?

Issues in Holistic \& Wellness, Models: Efficiency, Networks, and Effectiveness.

EBM- Efficacy, standardized, accessible, accurate, scientificallybased information.

The Module Paper has the aim of assisting students in learning objectives. The annotated bibliography supports all learning objectives. Students are to select their own reading, in consultation with other students and faculty, amounting to at least 1,000 pages. Students are to maintain an annotated bibliography of their reading and submit it to the Module Director at the completion of the module. Seminars, practical lessons, individual work, discussions, critical analyzes of article, project presentation. (Fig.2), (photo 1);

Format: This is a 300-level IS course taught in an active learning format. Writing is presented as a way to make thinking visible; interdisciplinary thinking is approached through staged writing (see hypertext link below). Student preparation, therefore, should emphasize reading and thinking prior to class so that reasoned dialog in class occurs regularly.

\section{Student Learning outcomes}

Students taking this course will learn to distinguish between theoretical ethics and applied ethics, communicate the major ethical theories and explain their assumptions, understand the general features (and limitations) of current bioethical discussion, evaluate common beliefs about ethics, conceptualize the nature of a medical relationship and understand the moral principles, identify the moral questions regarding medical practice and the health issues, identify the key values of medical decision-making, differentiate between ethically problematic or significant situations and situations which do not require ethical analysis, apply moral reasoning to specific situations and defend the conclusions of that reasoning, write clearly, eloquently and effectively about particular moral dilemmas, ethically evaluate the medical/health decisions and practices of others, direct and manage their own future learning about ethics. 


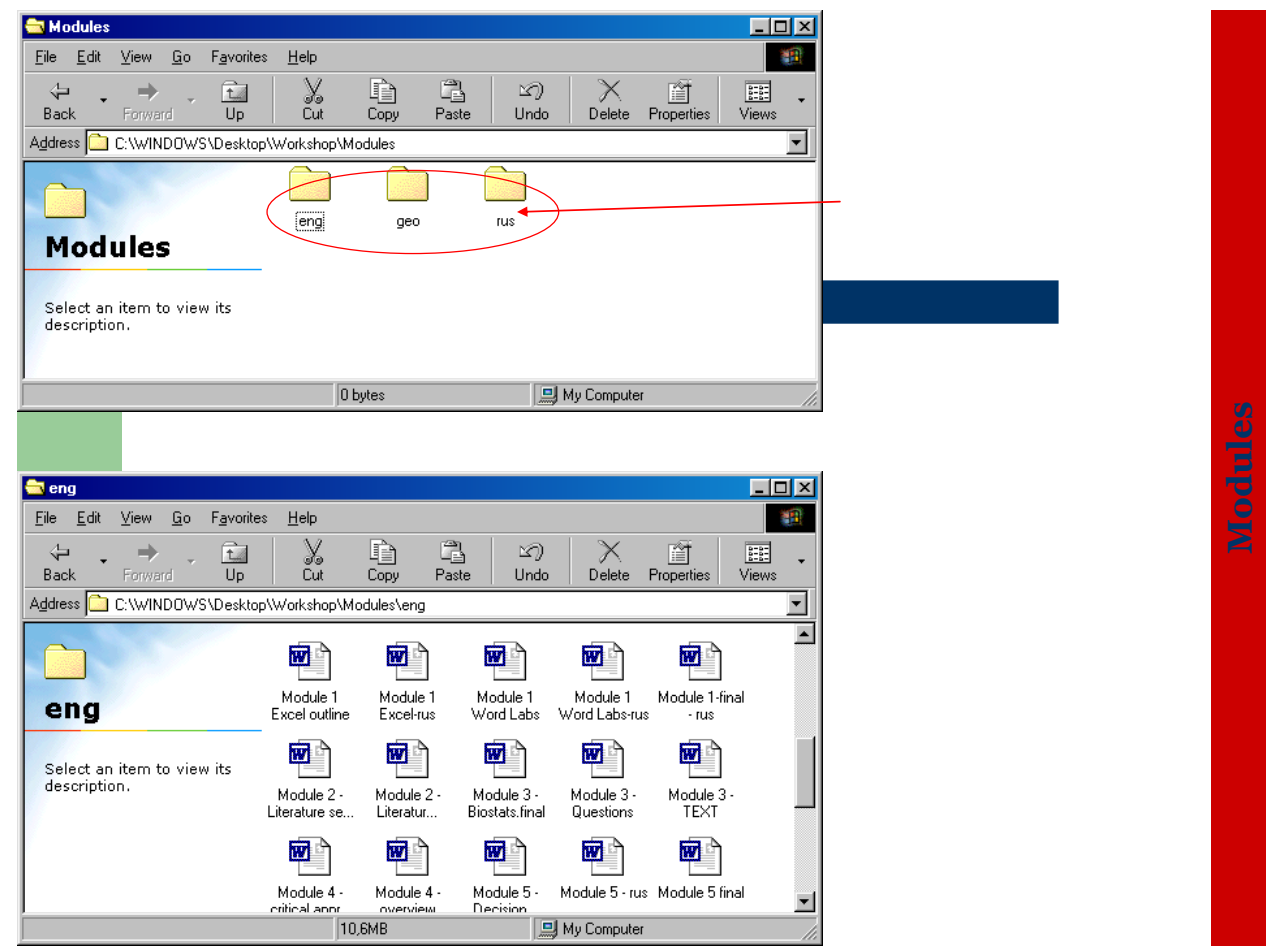

Fig.2 Teaching modules in different languages

\section{Conclusion:}

By the end of this course you should have demonstrated your capacity to: recognize, compare, and contrast the general "ways of thinking" of science (biology) and of philosophy (ethics).

Approach bioethical problems, break them into smaller, component parts (analysis), and discuss those analyses through oral and written communication, both individually and in groups.

Approach bioethical problems and propose solutions to them that transcend the disciplines of biology and philosophy, yet are solidly rooted in their respective ways-of-knowing.

Acquire and separate factual knowledge from opinion in the areas of science and philosophy.

Demonstrate good critical thinking (that is, clear, logical (coherent and relevant), broad, deep, and discriminating) in bioethics through speaking and writing.

Outcomes of CS and PBL are the problem-solving skills, selfdirected learning skills, ability to find and use appropriate resources, critical thinking, measurable knowledge base, performance ability, social and ethical skills, self-sufficiency and self-motivation, leadership skills, ability to work on a team, communication skills, proactive thinking, congruence with workplace skills. 


\section{References:}

1. Duch, B. J., Groh, S. E, \& Allen, D. E. (Eds.). (2001). The power of problem-based learning. Sterling, VA: Stylus.

2. Grasha, A. F. (1996). Teaching with style: A practical guide to enhancing learning by understanding teaching and learning styles.Pittsburgh: Alliance Publishers.

3. Ahlfeldt, S., Mehta, S. and Sellnow, T. (2005). Measurement and analysis of student engagement in university classes where varying levels of PBL methods of instruction are in use. Higher Education Research \& Development, 24 (1) 5-20.

4. Davis, B.D. (2009). Tools for teaching (2nd ed). San Francisco: Jossey-Bass.

5. Nilson, L.B. (2010). Teaching at its best: A research-based resource for college instructors (2nd ed). San Francisco: Jossey-Bass.

6. Svinicki, M. \& McKeachie, W. (2011). McKeachie's teaching tips: Strategies, research, and theory for college and university instructors (13th ed). Belmont, CA: Wadsworth.

7. Barrows, H. S. (1986). A taxonomy of problem?based learning methods.Medical education, 20(6), 481-486.

8. Savery, J. R., \& Duffy, T. M. (1995). Problem based learning: An instructional model and its constructivist framework. Educational technology, 35(5), 31-38.

9. Boud, D., \& Feletti, G. (1997). The challenge of problem-based learning. Psychology Press.

10. Barrows, H. S. (1996). Problem?based learning in medicine and beyond: A brief overview. New directions for teaching and learning, 1996(68), 3-12.

11. Anderson LW, Krathwohl D. A taxonomy for learning, teaching, and assessing: a revision of bloom's taxonomy of educational objectives, complete edition. Longman Publishing Group; White Plains, New York: 2000.

12. Bonney KM. Diffusion and osmosis: from gummy bears to celery stalks. 2014. National Center for Case Study Teaching in Science Case Collection. University of Buffalo. [Online.]http://sciencecases.lib.buffalo.edu/cs/files/diffusion_osmosis .pdf.

13. Bonney KM. An argument and plan for promoting the teaching and learning of neglected tropical diseases. J. Microbiol. Biol. Educ. 2013;14(2):183-188. doi: 10.1128/jmbe.v14i2.631. [PMC free article][PubMed] [Cross Ref] 
14. Carlson JA, Schodt DW. Beyond the lecture: case teaching and the learning of economic theory. J Econ Educ. 1995;26(1):17-28. doi: 10.1080/00220485.1995.10844853. [Cross Ref]

15. Dori YJ, Herscovitz O. Question-posing capability as an alternative evaluation method: analysis of an environmental case study. J Col Sci Teach. 1998;36(4):411-430. doi: 10.1002/(SICI)10982736(199904)36:4<411::AID-TEA2>3.0.CO;2-E. [Cross Ref]

16. Herreid CF, Schiller NA, Herreid KF, Wright C. In case you are interested: results of a survey of case study teachers. J Col Sci Teach. 2011;40(4):76-80.

17. Herreid CF. Case studies in science - a novel method of science education. J Col Sci Teach. 1994;23(4):221-229.

18. Herreid CF. The case of the dividing cell. 2003. National Center for Case Study Teaching in science Case Collection. University of Buffalo.

[Online.]http://sciencecases.lib.buffalo.edu/cs/files/mitosis_meiosis.p df.

19. Lawrence PR. The preparation of case material. In: Andrews KP, editor. The case method of teaching human relations and administration. Harvard University Press; Cambridge, MA: 1953. p. 215. 